\title{
Age-associated decrease in de novo donor-specific antibodies in renal transplant recipients reflects changing humoral immunity
}

\author{
Seraina von Moos ${ }^{1 *+} \mathbb{D}$, Gesa Schalk ${ }^{2 \dagger}$, Thomas F. Mueller ${ }^{1+}$ and Guido Laube ${ }^{2+}$
}

\begin{abstract}
Background: Older age at organ transplantation is associated with increased risk of infection and malignancy but reduced risk of cellular rejection. De novo donor-specific anti-HLA antibodies (dnDSA), are key biomarkers associated with reduced long-term allograft survival, yet there is a lack of data focusing on age-associated changes.

Methods: Development of $d n D S A$ was restrospectively analyzed in all subjects who received a kidney transplant at the University Hospital Zurich between 01/2006 and 02/2015. Follow up continued until 03/2016. The incidence of dnDSA in different age categories was compared with special focus on the extremes of age: children $<10$ years $(n=19)$ and adults $\geq 60$ years of age $(n=110)$.

Results: Incidence of dnDSA gradually decreased with age, with older recipients having a significantly lower risk ( $H R$ 0.21, $p=0.0224$ ) compared to pediatric recipients. Cumulative incidence of dnDSA at 2, 5 and 10 years was 6.2, 9.1 and $36 \%$ in the older recipients versus 5.3, 29.5 and $47.1 \%$ in pediatric recipients. Median time to development of dnDSA was similar (older 720 days, min 356, max 3646 days; children 1086 days, min 42, max 2474 days). Annual incidence was highest within the first two years after transplantation in the older recipients and peaked in years two to four in pediatric recipients. DnDSA were predominantly class II. More dnDSA were observed with cyclosporine as compared to tacrolimus.

Conclusion: Older kidney transplant recipients have a lower risk of developing dnDSA than pediatric recipients, pointing towards reduced humoral immune reactivity with increasing age. This observation raises the question of adjustment in immunosuppression.
\end{abstract}

Keywords: De novo donor specific antibodies, Aging, Older kidney transplant recipients, Pediatric kidney transplant recipients, Immunosenescence

\section{Introduction}

In recent years, interest in the changing immune reactivity over the life course has increased, as the number of older transplant recipients is steadily rising [1, 2]. Consideration of changing immune reactivity with increasing age, generally known as inflamm-aging and immunosenescence [3-6], is essential in the unique

\footnotetext{
*Correspondence: seraina.vonmoos@usz.ch

${ }^{\dagger}$ Seraina von Moos, Gesa Schalk, Thomas F Mueller, and Guido Laube contributed equally to this work.

'Department of Nephrology, University of Zurich and University Hospital Zurich, Rämistrasse 100, 8091 Zürich, Switzerland

Full list of author information is available at the end of the article
}

context of organ transplantation. While inflamm-aging collectively refers to the increased level of stimulation of the innate immune system, the concept of immunosenescence refers to alterations in the adaptive immune system with decreased numbers of naive $\mathrm{T}$ cells. The reduced ability to mount immune responses against novel antigens with increasing age is associated with increased risks of infection and malignancy and reduced vaccination responsiveness [3]. Particularly in the setting of organ transplantation, where the risk of rejection needs to be balanced with the risk of infections and malignancies [7], this changing immune reactivity with

(c) The Author(s). 2019 Open Access This article is distributed under the terms of the Creative Commons Attribution 4.0 International License (http://creativecommons.org/licenses/by/4.0/), which permits unrestricted use, distribution, and reproduction in any medium, provided you give appropriate credit to the original author(s) and the source, provide a link to the Creative Commons license, and indicate if changes were made. The Creative Commons Public Domain Dedication waiver (http://creativecommons.org/publicdomain/zero/1.0/) applies to the data made available in this article, unless otherwise stated. 
age should be considered in order to optimize immunosuppressive drug dosing [8]. In the field of organ transplantation, most studies comparing old with young transplant recipients have focused on T-cell responses [9] and have indeed described reduced frequency of acute T-cell mediated rejections in older kidney transplant recipients as compared to pediatric recipients $[10,11]$. Few studies have investigated antibody responses, i.e. development of $d n$ DSA against specific HLA-antigens despite increasing recognition of the key role for antibody-mediated rejection on long-term graft survival $[12,13]$. In addition, existing studies almost exclusively associate aging with old age and studies on immune responses in pediatric recipients are scarce. This study focuses on the changing immune reactivity of the humoral immune responses in kidney transplant recipients, comparing the incidence of $d n$ DSA in different age groups with a special focus on the those under 10 years and over 60 years of age.

\section{Methods}

\section{Patient population: inclusion and exclusion criteria}

In this longitudinal retrospective analysis all patients receiving a first single kidney transplant at the University Hospital of Zurich between January 2006 and February 2015 were eligible for inclusion. Follow up continued until March 2016. In depth analysis of changing immune-reactivity was performed for all children $<10$ years of age and for adults $\geq 60$ years of age.

In order to minimize bias from medication non-adherence known to be up to $43 \%$ in adolescent transplant recipients as compared to $22 \%$ in children and adults, we defined the pediatric reference cohort as children younger than 10 years of age [14-16]. As biological aging represents a spectrum, no clear clinical cut off for age has been defined for older transplant recipients. Changes associated with immunosenescence are described to start by 50 years of age $[9,17,18]$ and by general convention organ donors older than 60 years of age are considered extended criteria donors, due to differences in immunogenicity of older donor organs $[10,19]$. We therefore selected 60 years of age to define the older transplant recipient cohort [9]. Patients were excluded if the following were present: pre-existing DSA, missing donor typing information on DQ locus and possible DSA in the Luminex single bead assay (SAB) according to HLA associations, DSA MFI levels below 1000 in the Luminex SAB and patients with incomplete follow up data. The study was approved by the local ethics committee of Zurich (protocol number: KEK-ZH-Nr. 2017-00500).

Follow up of transplant patients, immunosuppression regimens and Luminex assays

During the first year after transplantation, patients were followed closely in the transplant clinic. Thereafter, patients were seen at least yearly. Induction therapy with basiliximab or thymoglobulin was used in patients at high risk for rejection. Maintenance immunosuppression consisted mostly of a calcineurin inhibitor (cyclosporine A or tacrolimus) and an anti-proliferative drug (generally mycophenolic acid). Steroids were withdrawn 6 months after transplantation in the majority of patients. Target trough levels at 6,12 and 24 months were $100-160 \mathrm{ng} /$ $\mathrm{ml}, 80-120 \mathrm{ng} / \mathrm{ml}, 50-80 \mathrm{ng} / \mathrm{ml}$ and $7-10 \mathrm{ng} / \mathrm{ml}$, 6-8 ng/ $\mathrm{ml}, 4-6 \mathrm{ng} / \mathrm{ml}$, for cyclosporine and tacrolimus respectively. When the post-transplant course was uncomplicated, HLA-specific antibody testing was done yearly. With graft dysfunction additional HLA-specific antibody testing was performed. Testing was done using LABScreen Mix Class I and II antibody screening kit (OneLambda, Canoga Park, CA). If the Luminex mix screening assay was positive, a specific Class I and/or Class II LAB Screen single-antigen assay was added (OneLambda, Canoga Park, CA). The data was analyzed using the kit specific HLA Fusion software (One Lambda). Antibodies to all loci (HLA-A, B- C, DR, DP and $\mathrm{DQ}$ ) were included. Donor and recipients were typed for HLA-A, B, DR and from 2012 onwards for DQ). Typing was done using PCR-SSP based molecular typing method (Protrans, Mannheim, Germany) [20]. Calculated mean fluorescence intensity (MFI) values were normalized against the internal negative control and the negative serum control. If an allele specific antibody against the donor was discovered in the single antigen Luminex screening assay, it was declared as DSA. A cutoff of 1000 MFI was chosen according to the Swiss Organ Procurement System (SOAS). The DSA with the highest MFI was defined as the peak DSA.

\section{Statistical analysis}

Occurrence of $d n$ DSA after transplantation in the two age groups was analyzed using Kaplan Meier curves. The log rank test was used for curve comparison. Peak MFI of $d n$ DSA was compared between the two groups with Mann Whitney U Test. The Chi square test was used to compare immunosuppressive medication in patients with and without development of $d n$ DSA. Graph Pad Prism 5 Software were used for statistical analyses.

\section{Results}

\section{Patient cohort}

Of 482 patients who received a single first kidney transplant between January 2006 and February 2015, 401 patients met inclusion criteria. A detailed patient flow chart is shown in Fig. 1. Patient distribution into different age groups and baseline characteristics are reported in Table 1. Median follow-up time did not significantly differ between the different age groups $(p=0.54$; Table 1). The average number of mismatches per locus 


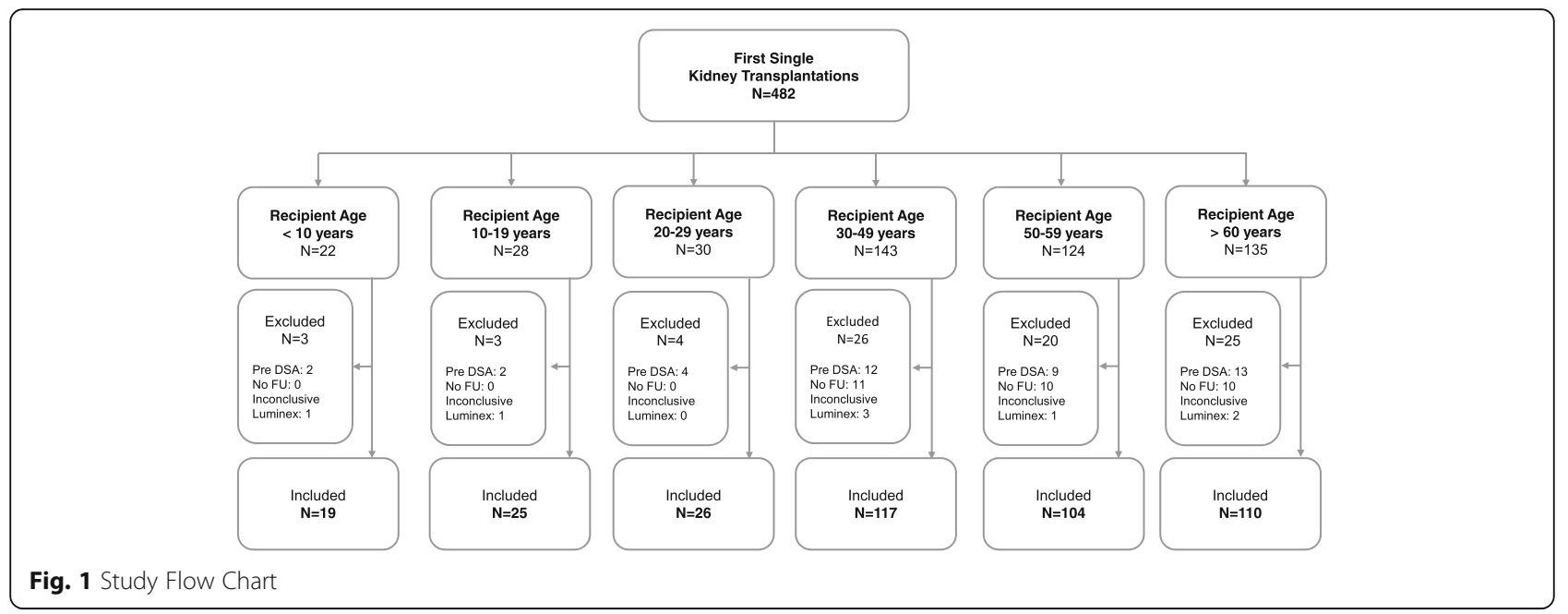

for the extremes of age groups are indicated in Additional file 1: Table S1.

\section{Gradual decrease of de novo DSA with increasing recipient age}

A significantly lower risk for development of $d n \mathrm{DSA}$ was observed in transplant recipients in the age groups $50-59$ years (HR 0.18; $p=0.014)$ and $\geq 60$ years of age (HR $0.21, p=0.22)$ as compared to children $(<10$ years of age). Risk of developing DnDSA was not significantly higher among adolescents compared with younger patients (HR 0.42, $p=0.20$ ). Overall, a tendency towards decreasing risk for development of $d n$ DSA with increasing age was observed, Fig. 2a. Comparison between the two extremes of age is highlighted in Fig. 2b. Cumulative prevalence of $d n \mathrm{DSA}$ for the different age groups is shown in Table 2. Further indepth analysis focused on the age extremes comparing older transplant recipients $\geq 60$ years (i.e. older recipient cohort) and children $<10$ years (i.e. pediatric recipient cohort). Cumulative incidence of $d n$ DSA at 2, 5 and 10 years for the older cohort was 6.2, 9.1 and $36 \%$ as compared to 5.3, 29.5 and $47.1 \%$ in the pediatric cohort. Annual incidence of $d n \mathrm{DSA}$ was highest in the first two years after transplantation for the older recipients, whereas annual incidence peaked between two and four years after transplantation in the pediatric recipients (Fig. 3a). Yet, median time to development of DSA was similar in the older recipient cohort (720 days; min 356, max 3646 days) and in the pediatric recipient cohort (1086 days; $\min 42$, $\max 2474$ days). Mean age at occurrence of $d n$ DSA was 71 years in the older recipient cohort and 8 years in the pediatric recipient cohort. Peak DSA was mostly a class II HLA antibody in both recipient cohorts (5 out of 6 in pediatric recipients; 9 out of 12 in older recipients), Additional file 1: Table S2. MFI of the peak $d n$ DSA was not statistically different between the pediatric recipients (mean peak MFI 6408) and the older recipients (mean peak MFI 7023, Additional file 1: Figure S1). Of note, similar percentages of patients displayed $d n$ DSA with MFI $>5000$ and with MFI $>10^{\prime} 000$ respectively (pediatric recipients: $3 / 6$ with $d n$ DSA MFI $>5000$ and 2 out of these with MFI $>10^{\prime} 000$, older recipients: $6 / 12$ with $d n$ DSA MFI $>5000$ and 4 out of these with MFI > $\left.10^{\prime} 000\right)$.

\section{Immunosuppression}

DnDSA developed significantly more often among older recipients receiving cyclosporine- compared with tacrolimus-based regimens (Fig. $3 \mathrm{~b}$ and Additional file 1: Table S3). A similar trend was observed in pediatric recipients, which did not reach statistical significance.

Table 1 Study population

\begin{tabular}{|c|c|c|c|c|c|c|}
\hline & Children $<10 y$ & Adolescent 10-19y & $20-29 y$ & $30-49 y$ & $50-59 y$ & Old $\geq 60 y$ \\
\hline Total number & 19 & 25 & 26 & 117 & 104 & 110 \\
\hline Mean age at transplantation & $6 \pm 3$ & $15 \pm 3$ & $25 \pm 3$ & $43 \pm 5$ & $56 \pm 3$ & $65 \pm 4$ \\
\hline Male gender, n (\%) & $10(53 \%)$ & $17(68 \%)$ & $16(62 \%)$ & $81(69 \%)$ & $66(63 \%)$ & $83(75 \%)$ \\
\hline Deceased transplant n (\%) & $11(58 \%)$ & $16(64 \%)$ & $3(12 \%)$ & $59(50 \%)$ & $60(58 \%)$ & $76(69 \%)$ \\
\hline $\begin{array}{l}\text { Median follow up time, days } \\
\text { (min; max) }\end{array}$ & $1971(356 ; 3420)$ & $1405(289 ; 3427)$ & $1788(343 ; 3444)$ & $1790(157 ; 3645)$ & $1841(154 ; 3624)$ & $1602(141 ; 3612)$ \\
\hline
\end{tabular}




\section{A}

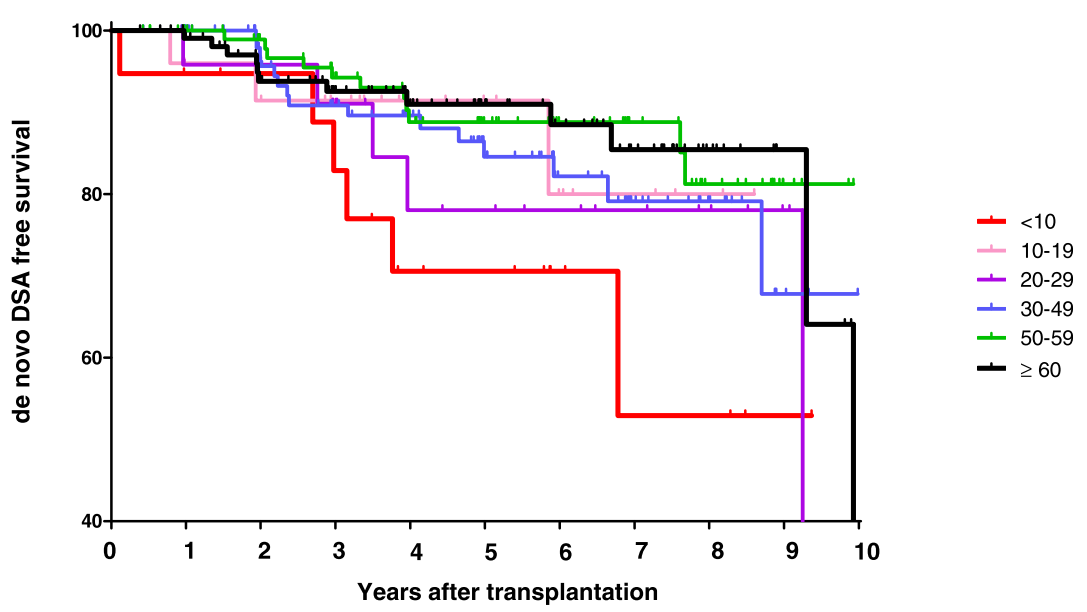

B

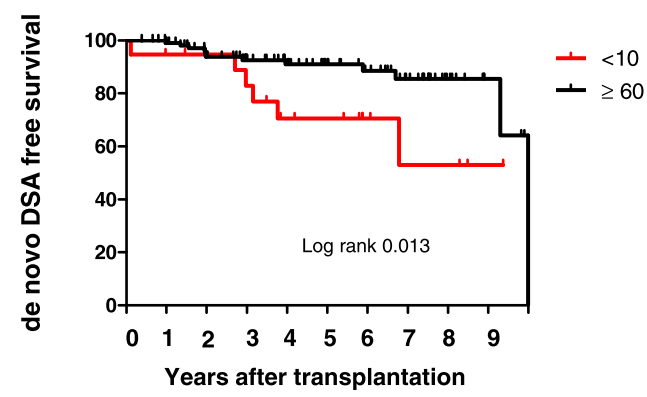

Subjects at risk for developing de novo DSA (related to Fig $2 A$ )

\begin{tabular}{|c|c|c|c|c|c|c|c|c|c|c|c|}
\hline Years & 0 & 1 & 2 & 3 & 4 & 5 & 6 & 7 & 8 & 9 & 10 \\
\hline$<10$ & 19 & 17 & 16 & 14 & 10 & 9 & 5 & 3 & 3 & 1 & 0 \\
\hline $10-19$ & 25 & 21 & 20 & 17 & 11 & 9 & 6 & 4 & 2 & 0 & 0 \\
\hline $20-29$ & 26 & 21 & 20 & 17 & 12 & 11 & 9 & 7 & 5 & 2 & 0 \\
\hline $30-49$ & 117 & 105 & 83 & 73 & 59 & 45 & 29 & 19 & 12 & 3 & 0 \\
\hline 50-59 & 104 & 95 & 86 & 77 & 59 & 47 & 34 & 26 & 16 & 4 & 0 \\
\hline$\geq 60$ & 110 & 100 & 82 & 66 & 55 & 43 & 34 & 25 & 12 & 4 & 0 \\
\hline
\end{tabular}

Subjects in each age group at risk for developing $d n D S A$ at a

Fig. 2 Cumulative incidence of dnDSA after kidney transplantation as determined by Kaplan Meier survival curves. a Comparison between all age groups, b) Comparison between the older recipient cohort and the pediatric recipient cohort using Log rank test. Subjects at risk for developing dnDSA in each time period are shown

Table 2 Risk of development of dnDSA in different age groups

\begin{tabular}{llllll}
\hline & Children < 10y & Adolescent 10-19y & 20-29y & $30-49 y$ & Old $\geq$ 60y \\
\hline Cumulative prevalence dnDSA & $32 \%(6 / 19)$ & $12 \%(3 / 25)$ & $19 \%(5 / 26)$ & $13 \%(15 / 117)$ & $11 \%(11 / 104)$ \\
Hazard ratio, $p$ & - & HR $0.42 p=0.205$ & HR 0.52 $p=0.312$ & HR $0.35 p=0.088 \quad$ HR $0.18 p=0.014 \quad$ HR 0.21 $p=0.022$ \\
\hline
\end{tabular}



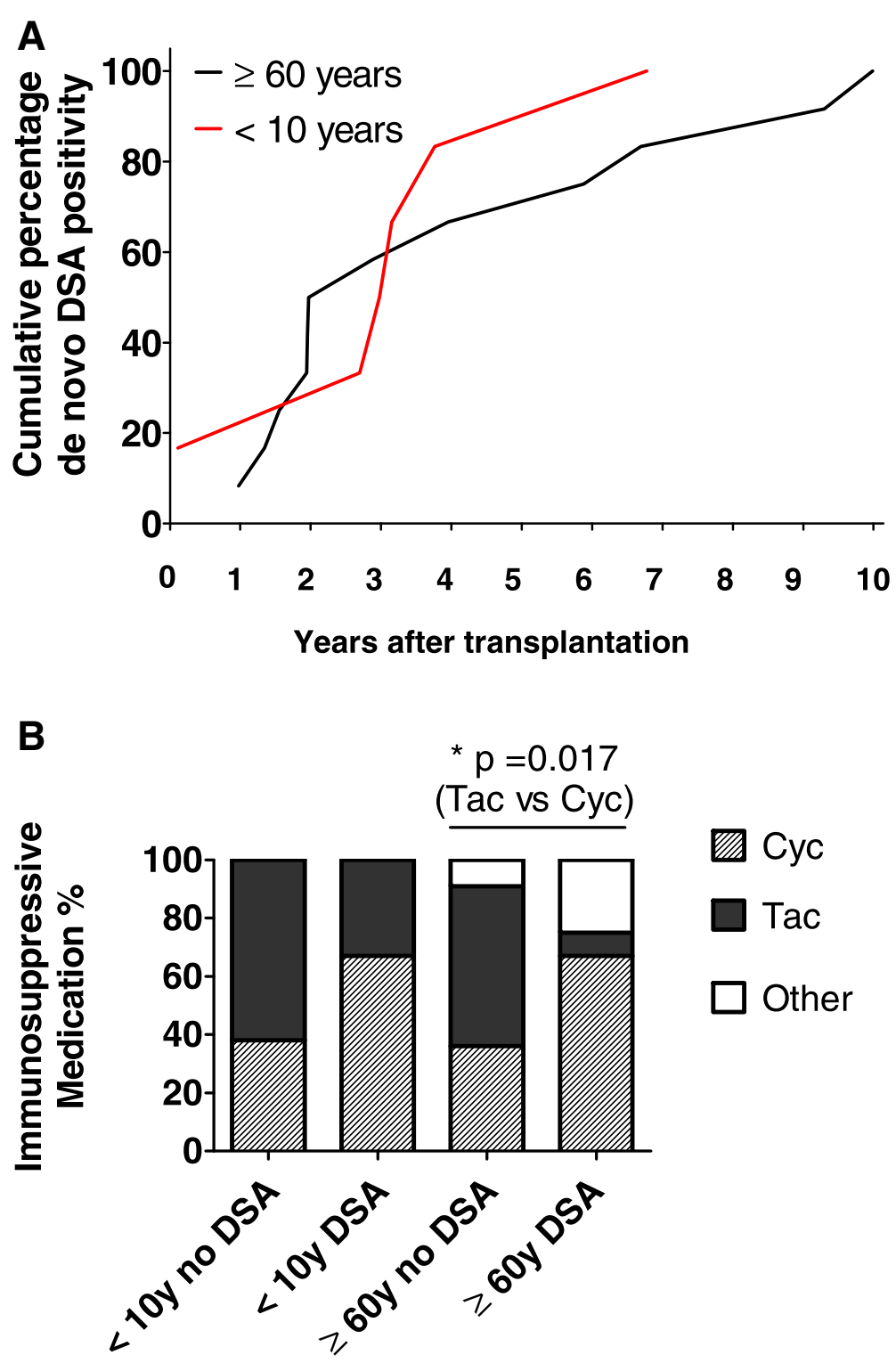

Fig. 3 a Cumulative percentage of de novo DSA positivity in the cohort of recipients developing a donor specific humoral immune response: $n=12$ in the older cohort and $n=6$ in the pediatric cohort. $\mathbf{b}$ Comparison of immunosuppressive medication (Cyclosporine $=$ Cyc, Tacrolimus $=$ Tac) at time point of detection of de novo DSA between recipients with and without de novo donor specific humoral immune response in both cohorts, i.e. older and pediatric patients. Comparison using Chi-square test

\section{Discussion}

Due to demographic changes, increasing numbers of patients aged over 60 years are being transplanted $[1,2]$. Hence, investigation of changing immune reactivity over the life course is increasing. In general, older recipient age is an independent risk factor for post-transplant mortality in all solid organ transplantations [9, 21], with the highest risk being infection-associated death followed by cardiovascular death and malignancies [22]. In contrast, the risk of acute cellular rejection is lower in older transplants recipient compared with pediatric recipients $[23,24]$. These observations reflect changes in the adaptive immune system summarized by the terms 'immunosenescence' and 'inflamm-aging'. The reduced risk of acute cellular rejections is consistent with thymic involution and the limited $\mathrm{T}$-cell receptor repertoire observed with aging $[6,9,21]$. Additionally, humoral immune responses in older patients have also been shown to be altered, with increased memory responses and a skewed B cell repertoire $[11,25,26]$ which is more specialized but less plastic to mount humoral immune responses. Together with the reduced frequency of naïve $\mathrm{T}$ cells these changes are associated with increased risk of infections [11, 26]. By contrast, the heightened 
subclinical inflammation associated with inflamm-aging and increased reactivity of the innate immune system potentially contributes to increased cardiovascular risk among older transplant recipients. Together, these aspects highlight the complex nature of immunological changes associated with aging.

Given the major role of antibody-mediated responses in determining long-term graft survival [12, 13], we analyzed changes in humoral immune reactivity with increasing age by investigating the incidence of $d n \mathrm{DSA}$ in older kidney transplant recipients compared with pediatric kidney transplant recipients. Our results indicate that the risk of developing $d n \mathrm{DSA}$ is 4.8 to 5.6 times lower in older recipients as compared to pediatric recipients (older aged $\geq 60$ years HR $0.21 ; p=0.0224$ ). Interestingly, we observed that the changing reactivity of the immune system may begin around age 50 years (HR $0.18, p=0.014$ ). Of note, the annual incidence of $d n$ DSA was highest during the first two years post-transplantation in the older recipients, while the annual incidence of $d n \mathrm{DSA}$ peaked between years two and four after transplantation in pediatric recipients These early post-transplant years are a time when immunosuppressive drug doses are generally reduced. Consistent with the literature, the majority of $d n$ DSA were directed against HLA class II, more specifically against HLA DQ locus [27, 28] and $d n \mathrm{DSA}$ occurred significantly more frequently with cyclosporine- rather than tacrolimus-based immunosuppression [22].

To our knowledge, this is the first study directly comparing the incidence of $d n \mathrm{DSA}$ in older vs. pediatric kidney transplant recipients. Few small studies have investigated the development of $d n \mathrm{DSA}$ in older patients from the European senior program, reporting variable cumulative prevalences for $d n$ DSA between 20 and 30\% at 5 to 10 years post transplantation [22, 29], numbers that are higher than those observed in our cohort. Yet, development of $d n$ DSA after kidney transplantation is highly variable with reports ranging from cumulative prevalences from 13 to $30 \%$ in non-sensitized adult kidney transplant recipients [30, 31]. This variability could reflect differences in antibody MFI cut offs, frequency of testing and baseline immunosuppression. With respect to the young cohort, our data are consistent with results from other centers reporting a cumulative prevalence between 20 and $36 \%$ at 5 to 10 years after transplantation [27, 32, 33].

A major strength of our study is the direct comparison between the different age groups of transplant recipients treated and followed up at the same hospital and tested for development of $d n \mathrm{DSA}$ in the same laboratory. To our knowledge this is the first study to directly compare development of $d n \mathrm{DSA}$ across patient age groups simultaneously and is therefore novel. We specifically set the age limit for definition of the pediatric recipient cohort at age younger than 10 to minimize the confounder of non-adherence, which is a relevant problem in adolescent recipients [34-36]. All but one pediatric recipient developed $d n \mathrm{DSA}$ at age $\leq 10$ years of age (Additional file 1: Table S4). Hence, the differences in incidence and prevalence of $d n \mathrm{DSA}$ are most likely due to age-associated changes in immune reactivity and do not reflect differences in medication adherence. Assessment of medication adherence was however not possible in this retrospective study. The study does have several limitations. Subject numbers included in the extremes of age groups were different. Given the retrospective nature of the study, data regarding $\mathrm{C} 1 \mathrm{q}$ binding of the $d n \mathrm{DSA}$ was not available. We did not investigate the effect of donor-recipient age ratio, which is another limitation given the known effect of organ age on immune reactivity $[10,19]$. Additionally, at our center, we do not perform protocol biopsies, making a statement with respect to histological changes related to development of $d n$ DSA impossible. Similarly, due to small patient numbers, data on graft survival would not be meaningful and in older adults is also highly impacted by comorbidities and not only rejection episodes [37]. Also, chronological age might not be congruent with biological age, considering the multiple modifying extrinsic factors such as nutrition, exercise and previous exposure to microorganisms [5] which adds to the complexity of changing pharmacodynamics and pharmacokinetics of immunosuppressive drugs with age [38]. Pharmacokinetic studies were not possible in this retrospective analysis.

In conclusion, this study adds to current knowledge having investigated humoral immune responses after kidney transplantation over the whole age spectrum. A gradual decrease in incidence of $d n \mathrm{DSA}$, with age was observed, underscored by a significantly lower risk of $d n \mathrm{DSA}$ in the older recipient cohort as compared to the pediatric recipient cohort. Our observations may have practical implications with respect to immunosuppressive medication dosing and suggest that medication levels should be tailored to the individual needs reflecting the adaptive changes of immune reactivity associated with aging. Further prospective studies, including larger patient numbers and recipients of different solid organ transplants, with monitoring of medication adherence, including pharmacodynamic and pharmacokinetic studies as well as biomarkers associated with biological aging [3, 4, 39] are needed to confirm our data and to introduce a practical guidance on immunosuppressive medication dosing in accordance to transplant recipient age. 


\section{Additional file}

Additional file 1: Figure S1. Comparison of MFI Peak de novo DSA Table S1. Average Mismatches. Table S2. Peak dnDSA Specifity for the individual patients. Table S3. Immunosuppression. Table S4. Individual characteristics of the pediatric recipients developing de novo DSA. (DOCX $35 \mathrm{~kb})$

\section{Abbreviations}

dnDSA: de novo donor specific antibodies; HLA: Human leukocyte antigen; Luminex SAB: Luminex single antigen bead assay; MFI: Mean fluorescence intensity

\section{Acknowledgements}

We thank Valerie Luyckx for proofreading. We thank Barbara Rüsi, HLA

Laboratory University Hospital Zurich for helpful discussions.

\section{Funding}

This study was not funded.

\section{Availability of data and materials}

The actual data is extracted from the KISIM, which is the database used by medical doctors at the University Hospital of Zurich and from Phönix, the database that is used by medical doctors at the University Children's Hospital of Zurich.

\section{Authors' contributions}

SvM and GS were involved in the study design, data collection, statistical analysis and draft work as well as finalization of the manuscript. TM and GL contributed by the study design and the finalization of the manuscript. All authors read and approved the final manuscript.

\section{Ethics approval and consent to participate}

The study was approved by the local ethics committee of Zurich (protocol number: KEK-ZH-Nr. 2017-00500).

\section{Consent for publication}

Not applicable.

\section{Competing interests}

The authors declare that they have no competing interests.

\section{Publisher's Note}

Springer Nature remains neutral with regard to jurisdictional claims in published maps and institutional affiliations.

\section{Author details}

'Department of Nephrology, University of Zurich and University Hospital Zurich, Rämistrasse 100, 8091 Zürich, Switzerland. ${ }^{2}$ Department of Nephrology, University of Zurich and University Children's Hospital, Steinwiesstrasse 75, 8032 Zurich, Switzerland.

Received: 18 November 2018 Accepted: 25 April 2019

Published online: 09 May 2019

\section{References}

1. McKay D, Jameson J. Kidney transplanqtation and the ageing immune system. Nat Rev Nephrol. 2012;8(12):700-8.

2. Segall L, Nistor I, Pascual J, Mucsi I, Guirado L, Higgins R, et al. Criteria for and appropriateness of renal transplantation in elderly patients with endstage renal disease: a literature review and position statement on behalf of the European renal association-European Dialysis and transplant association Descartes working group and European renal best practice. Transplantation. 2016;100(10):e55-65.

3. Pawelec G. Age and immunity: what is "immunosenescence"? Exp Gerontol. 2018;105:4-9.

4. Rea IM, Gibson DS, McGilligan V, McNerlan SE, Alexander HD, Ross OA. Age and age-related diseases: role of inflammation triggers and cytokines. Front Immunol. 2018:9:586
5. Fulop T, Larbi A, Dupuis G, Le Page A, Frost EH, Cohen AA, et al. Immunosenescence and Inflamm-aging as two sides of the same coin: friends or foes? Front Immunol. 2017;8:1960.

6. Mueller TF. Phenotypic changes with immunosuppression in human recipients. Front Biosci. 2003;8:d1254-74.

7. Cippa PE, Schiesser M, Ekberg H, van Gelder T, Mueller NJ, Cao CA, et al. Risk stratification for rejection and infection after kidney transplantation. Clin J Am Soc Nephrol. 2015;10(12):2213-20.

8. Lehner LJ, Staeck O, Halleck F, Liefeldt L, Bamoulid J, Budde K. Need for optimized immunosuppression in elderly kidney transplant recipients. Transplant Rev (Orlando). 2015;29(4):237-9.

9. Colvin MM, Smith CA, Tullius SG, Goldstein DR. Aging and the immune response to organ transplantation. J Clin Invest. 2017;127(7):2523-9.

10. Tullius SG, Milford E. Kidney allocation and the aging immune response. N Engl J Med. 2011:364(14):1369-70.

11. de Bourcy CF, Angel CJ, Vollmers C, Dekker CL, Davis MM, Quake SR. Phylogenetic analysis of the human antibody repertoire reveals quantitative signatures of immune senescence and aging. Proc Natl Acad Sci U S A. 2017:114(5):1105-10

12. Sellares J, de Freitas DG, Mengel M, Reeve J, Einecke G, Sis B, et al. Understanding the causes of kidney transplant failure: the dominant role of antibody-mediated rejection and nonadherence. Am J Transplant. 2012; 12(2):388-99.

13. Loupy A, Hill GS, Jordan SC. The impact of donor-specific anti-HLA antibodies on late kidney allograft failure. Nat Rev Nephrol. 2012;8(6):348-57.

14. Dobbels F, Van Damme-Lombaert R, Vanhaecke J, De Geest S. Growing pains: non-adherence with the immunosuppressive regimen in adolescent transplant recipients. Pediatr Transplant. 2005;9(3):381-90.

15. Dobbels F, Ruppar T, De Geest S, Decorte A, Van Damme-Lombaerts R, Fine $\mathrm{RN}$. Adherence to the immunosuppressive regimen in pediatric kidney transplant recipients: a systematic review. Pediatr Transplant. 2010;14(5):603-13.

16. Weitz M, Heeringa S, Neuhaus TJ, Fehr T, Laube GF. Standardized multilevel transition program: does it affect renal transplant outcome? Pediatr Transplant. 2015:19(7):691-7.

17. Demers P, Moffatt S, Oyer PE, Hunt SA, Reitz BA, Robbins RC. Long-term results of heart transplantation in patients older than 60 years. J Thorac Cardiovasc Surg. 2003;126(1):224-31.

18. Snell Gl, De Hoyos A, Winton T, Maurer JR. Lung transplantation in patients over the age of 50. Transplantation. 1993;55(3):562-6.

19. Pratschke J, Dragun D, Hauser IA, Horn S, Mueller TF, Schemmer $P$, et al Immunological risk assessment: the key to individualized immunosuppression after kidney transplantation. Transplant Rev (Orlando). 2016;30(2):77-84.

20. Forssmann U, Mytilineos J, Scherer S, Opelz G. A method for HLA-DQA typing by the PCR-SSP technique. Transpl Int. 1994;7(Suppl 1):S515-8.

21. Heinbokel T, Hock K, Liu G, Edtinger K, Elkhal A, Tullius SG. Impact of immunosenescence on transplant outcome. Transpl Int. 2013:26(3):242-53.

22. Jacobi J, Beckmann S, Heller K, Hilgers KF, Apel H, Spriewald B, et al. Deceased donor kidney transplantation in the Eurotransplant senior program (ESP): a single-center experience from 2008 to 2013. Ann Transplant. 2016:21:94-104

23. Lufft $V$, Tusch $G$, Offner $G$, Brunkhorst R. Kidney transplantation in children: impact of young recipient age on graft survival. Nephrol Dial Transplant. 2003;18(10):2141-6.

24. Tejani AH, Stablein DM, Sullivan EK, Alexander SR, Fine RN, Harmon WE, et al. The impact of donor source, recipient age, pre-operative immunotherapy and induction therapy on early and late acute rejections in children: a report of the north American pediatric renal transplant cooperative study (NAPRTCS). Pediatr Transplant. 1998;2(4):318-24

25. Cancro MP, Hao Y, Scholz JL, Riley RL, Frasca D, Dunn-Walters DK, et al. B cells and aging: molecules and mechanisms. Trends Immunol. 2009:30(7):313-8.

26. Hao Y, O'Neill P, Naradikian MS, Scholz UL, Cancro MP. A B-cell subset uniquely responsive to innate stimuli accumulates in aged mice. Blood. 2011:118(5):1294-304

27. Kim JJ, Balasubramanian R, Michaelides G, Wittenhagen P, Sebire NJ Mamode $\mathrm{N}$, et al. The clinical spectrum of de novo donor-specific antibodies in pediatric renal transplant recipients. Am J Transplant. 2014; 14(10):2350-8

28. Lionaki S, Panagiotellis K, Iniotaki A, Boletis JN. Incidence and clinical significance of de novo donor specific antibodies after kidney transplantation. Clin Dev Immunol. 2013;2013:849835. 
29. Halleck F, Khadzhynov D, Liefeldt L, Schrezenmeier E, Lehner L, Duerr M, et al. Immunologic outcome in elderly kidney transplant recipients: is it time for HLA-DR matching? Nephrol Dial Transplant. 2016;31(12):2143-9.

30. Zhang R. Donor-specific antibodies in kidney transplant recipients. Clin J Am Soc Nephrol. 2017.

31. Konvalinka A, Tinckam K. Utility of HLA antibody testing in kidney transplantation. J Am Soc Nephrol. 2015;26(7):1489-502.

32. Rusai K, Dworak J, Potemkina A, Fischer G, Csaicsich D, Arbeiter K, et al. Donor-specific HLA antibodies and graft function in kidney-transplanted children - the Vienna cohort. Pediatr Transplant. 2016;20(4):507-14.

33. Miettinen J, Perasaari J, Lauronen J, Qvist E, Valta H, Pakarinen $\mathrm{M}$, et al. Donor-specific HLA antibodies and graft function in children after renal transplantation. Pediatr Nephrol. 2012;27(6):1011-9.

34. Shaw RJ, Palmer L, Blasey C, Sarwal M. A typology of non-adherence in pediatric renal transplant recipients. Pediatr Transplant. 2003;7(6):489-93.

35. Varnell CD Jr, Rich KL, Nichols M, Dahale D, Goebel JW, Pai ALH, et al. Assessing barriers to adherence in routine clinical care for pediatric kidney transplant patients. Pediatr Transplant. 2017;21(7).

36. Prendergast MB, Gaston RS. Optimizing medication adherence: an ongoing opportunity to improve outcomes after kidney transplantation. Clin J Am Soc Nephrol. 2010;5(7):1305-11.

37. Meier-Kriesche HU, Ojo AO, Cibrik DM, Hanson JA, Leichtman AB, Magee JC, et al. Relationship of recipient age and development of chronic allograft failure. Transplantation. 2000;70(2):306-10.

38. Sera LC, MCPherson ML. Pharmacokinetics and pharmacodynamic changes associated with aging and implications for drug therapy. Clin Geriatr Med. 2012;28(2):273-86

39. Pawelec G, Larbi A, Derhovanessian E. Senescence of the human immune system. J Comp Pathol. 2010;142(Suppl 1):S39-44.

Ready to submit your research? Choose BMC and benefit from:

- fast, convenient online submission

- thorough peer review by experienced researchers in your field

- rapid publication on acceptance

- support for research data, including large and complex data types

- gold Open Access which fosters wider collaboration and increased citations

- maximum visibility for your research: over $100 \mathrm{M}$ website views per year

At $\mathrm{BMC}$, research is always in progress.

Learn more biomedcentral.com/submissions 